\title{
UMA ESCUTA DAS MIGRAÇÕES, MÚSICOS HAITIANOS E PERFORMANCES EM DESLOCAMENTO
}

LISTENING BASED ON MIGRATION, HAITIAN MUSICIANS AND

PERFORMANCES WITH DISPLACEMENT

\section{Daniel Stringini}

PPGM-UNIRIO

\begin{abstract}
Resumo: Em diálogo com o trabalho de músicos e coletivos haitianos no Sul do Brasil, proponho uma escuta da cidade a partir da escuta destes fluxos migratórios. Acompanhando a trajetória e deslocamento de músicos e de suas músicas ao longo da cidade, reflito sobre os encontros e tensões entre "mundos sonoros migrantes" e "mundos sonoros locais". Sugiro que frentes musicais negras e migrantes em uma cidade majoritariamente branca têm produzido novas situações, apontado questionamentos e rearranjado territórios urbanos.
\end{abstract}

Palavras-chave: músicos haitianos, migração haitiana, etnomusicologia, escuta.

\begin{abstract}
In dialogue with Haitian musicians and ensembles in southern Brazil, I propose to listen to the city based on listening to these migrant flows. Following the paths and displacement of musicians and their music throughout the city, I reflect on the encounter and tensions between "migrating sound worlds" and "local sound worlds". I suggest that black musical fronts in a mostly white city have produced new situations, pointed out questions and rearranged urban territories.
\end{abstract}

Keywords: Haitian musicians, Haitian migration, ethnomusicology, listening. 
A temática música e migração já a algum tempo vem ocupando pesquisadores e pesquisadoras no campo da etnomusicologia. Trabalhos como os de Adelaida Reyes (1999) e Kay Shelemay (1998), respectivamente entre vietnamitas e entre comunidades judaicas nos Estados Unidos, o de John Baily (2005) com músicos afegãos exilados, ou o de Susana Sardo (2010) com a diáspora goesa são algumas referências nos estudos com migração no campo da etnomusicologia' (LÜHNING, TUGNY, 2016).

Os trabalhos de Ursula Hemetek são também exemplos que entrecruzam música e migração. Ao abordar as práticas de múltiplos grupos minoritários migrantes na cidade de Viena (HEMETEK, 2010), ela diz que, entre outras questões, as produções sonoras destes grupos desafiariam, naquele contexto de deslocamento, as noções de "raízes". Ela diz isto se referindo a produção de estereótipos e estigmas atribuídos a um imaginário em torno de sociedades migrantes, refugiadas e diaspóricas. Ela aponta o quanto os músicos desenvolvem um repertório musical que desestabiliza determinado "horizonte de possibilidades" imposto a esses grupos sociais. Como ponto de partida, aqui, tomo o trabalho desta autora e o conecto com a etnografia entre músicos e comunidades haitianas no Sul do Brasil em que estou envolvido. Faço isto no sentido de, mais especificamente, pensar naquilo que estaria sendo desafiado através e a partir de práticas musicais migrantes haitianas na cidade de Chapecó, Santa Catarina. Quais questões estariam, então, sendo colocadas em jogo pelas produções sonoras de músicos e grupos haitianos em uma cidade média, "agroindustrial", "universitária", "migrante” e "indígena"?²

1 Etnomusicologia é um campo interdisciplinar que se propõem a pensar a música e o som como algo inseparável de dimensões étnico-raciais, sociais, econômicas, políticas e outras. 2 Estes termos são alguns dos que tem marcado a cidade,
Perseguindo o que coloca Hemetek, sugiro pensarmos em que medida, por meio de movimentações musicais, cenas artísticas e territorializações sonoras, imaginários e estigmas seriam desafiados nestes fluxos migratórios, e o quanto nos apontariam aspectos que excedem o próprio sonoro. Ao trazer, aqui, as performances de músicos haitianos, pretendo colocar em discussão aquilo que é mobilizado por elas e os discursos que as envolvem. Tenho sugerido que as práticas sonoro musicais migrantes têm criado novas situações e reterritorializado esta cidade do Sul.

Seguindo as pistas abertas por estas performances, proponho aqui uma escuta que se dê a partir da perspectiva da migração haitiana. Uma escuta da cidade que se dê a partir das sonoridades de músicos e comunidades haitianas. Minha intenção é delinear produções sonoras que são atravessadas por encontros e tensionamentos, xenofobias e racismos, e desestabilizar entendimentos fixos em torno de noções como música, som e "diálogo/integração musical". ${ }^{3}$ Por práticas musicais tenho considerado as performances musicais, suas gravações, assim como os espaços onde elas tem sido performatizadas tais como festas, shows, home estúdios, igrejas, universidades, praças, escolas de música, parques, ruas e espaços virtuais. Sugerir uma escuta migrante significa situar uma prática musical que desloca, que conecta. Josh Kun (2019) elabora um "ouvir os sonideros" (DJs mexicanos migrantes na fronteira dos Estados Unidos) em

seja como reinvindicações de grupos sociais, como é o caso da reivindicação por uma cidade migrante, seja pelos interesses de elites econômicas em torno dos rótulos de "cidade de emprego" e de "cidade agroindustrial".

3 Ao desconsiderarem as possibilidades da música enquanto também produtora de violências (ARAÚJO 2006, CUSICK, 2006), tais entendimentos têm contribuído para a manutenção de exclusões e epistemicídios no campo da música (EWELL, 2020; QUEIROZ, 2017, 2020). 
termos de uma escuta da mobilidade cultural. ${ }^{4}$

A noção de escuta tem figurado no campo da etnomusicologia e, nas últimas décadas, nos Sound Studies, campo que tem colocado como central a experiência sonora/auditiva nos estudos sociais. A recente publicação Remapping Sound Studies (2019), no entanto, tem problematizado a ausência de perspectivas produzidas no "Sul Global" e apontado que estes estudos têm ocorrido, sobretudo, em grandes centros urbanos. Diante disso, pensar questões em torno de som e escuta em uma cidade média como Chapecó, e a partir de uma migração Sul-Sul, nos coloca outros questionamentos.

Tocar, ouvir e conviver com músicos do Haiti tem me feito ficar atento a como os espaços da cidade têm se alterado diante de fluxo globais que estão ligados, por sua vez, aos modos como o capitalismo contemporâneo se reapresenta (SASSEN, 2016). As músicas que têm ocupados os espaços e que escapam das casas, dos carros, das igrejas, das festas, dos locais de ensaios têm demarcado territórios sônicos e reconfigurado a paisagem sonora da cidade (INGOLD, 2008; LA BARRE, 2012). As festas organizadas pelas comunidades haitianas, com seu volume sonoro, por exemplo, amplificam e reafirmam presenças ao longo destes territórios.

Para este artigo, irei focalizar a produção de dois artistas/coletivos haitianos buscando situar como ambas as experiências evidenciam questões étnico-raciais neste fluxo migratório, como apontam novas articulações entre sujeitos, comunidades, sonoridades e territórios, e como lançam questões fundamentais para pensarmos a própria cidade e a sociedade hospedeira. No primeiro momento apresentarei aspectos em torno de uma composição do mú

4 Nesta direção, também Tom Western (2020) propõe uma "escuta com deslocamento" para repensar a condição atual de refugiados na cidade de Atenas. sico, produtor e DJ Malko J., e posteriormente insights em torno de uma performance virtual do coletivo musical Valide Konpa. A partir da escuta destas experiências e do que elas suscitam, localizarei a dimensão sonoro-musical migrante-haitiana como produção de outras perspectivas e de outros territórios existenciais em face de um contexto hostil e discriminatório.

Sandro Mezzadra (2012), ao tratar sobre migração, capitalismo e subjetividade, e entendendo os grupos migrantes enquanto comunidades políticas, referindo-se a suas potencialidades em desafiar os limites de nossa imaginação política, cita a autora Bonnie Honig:

Fazendo uma crítica bastante convincente da homologia entre a imagem "xenofílica" do estrangeiro como alguém que tem algo a oferecer, e da imagem "xenofóbica" do estrangeiro interessado em "tomar" algo da sociedade que ele ou ela escolhe para viver, Honig inverte os termos e propõe que pensemos este "tomar" como aquilo mesmo que os imigrantes têm a nos oferecer (HONIG, 2001, p. 99). Em outras palavras, as práticas pelas quais, de acordo com a autora, a cidadania dos migrantes se expressa (mesmo nas condições de exclusão radical da cidadania juridicamente codificada) são vistas como questionadoras das bases estruturantes da própria democracia. (MEZZADRA, 2012, p.95)

Interessa, aqui, considerar o que este recente fluxo haitiano no Brasil provoca e coloca em relevo. Nosso foco aqui é em torno do sonoro, contudo, mudanças ativadas por esse regime migratório podem ser observadas em várias outras esferas. ${ }^{5}$ Meus interlocutores (universitá-

\footnotetext{
5 Menciono o sistema de ingresso especial para alunos haitianos (Pro-Haiti) iniciado em 2014 pela Universidade Federal da Fronteira Sul, com campus na cidade de Chapecó, que tem sido entendido como resultado de diálogos entre comunidades haitianas e representantes políticos; e menciono também, como um todo, as políticas de migração brasileira.
} 
rios, operários, empreendedores, músicos) cruzam múltiplos espaços urbanos e tem produzido questionamentos que colocam em relação, por exemplo, universidades, igrejas, escolas de música, indústrias, comércio, estúdios, bares, casas de shows. Escutar os territórios urbanos através de uma escuta das práticas sonoras haitianas também tem criado, assim, espaços para que outras narrativas sobre a cidade e sobre migrações emerjam. Ouvir a cidade a partir destes músicos/grupos migrantes, implica em reconsiderar também um contexto de racismo histórico e estrutural brasileiro.

Tenho encontrado pontos de contato com o que apresento aqui, em Chalcraft, Segarra e Hikiji (2017, p.309) ao abordarem a performance de artistas e músicos congoleses na cidade de São Paulo: ao se referirem à performance proposta pelo artista multidisciplinar Shambuyi e pelo músico Yannick, dizem que eles "continuam a desafiar nossa compreensão da cidade e de sua experiência imigrante".

No atual contexto pandêmico, outras formas de ocupação, agora também virtuais, da cidade tem ganhado espaço. Vídeos, vídeo clipes, plataformas streamings, gravações caseiras, criação de home estúdios, debates virtuais e transmissões online de shows tornam-se práticas de convivências possíveis. É envolvido nesta situação dramática que apresento estas experiências com o sonoro. Ainda que o primeiro caso que será apresentado aqui tenha ocorrido antes da pandemia, a música em questão seguiu circulando nesse momento de enclausuramento e, junto com outros vídeos e produções do artista amplificaram seu trabalho e possibilitaram outros tipos de conexões.

\section{Sobre a cidade e deslocamentos}

Chapecó, com cerca de 220 mil habitantes, é uma cidade central da região oeste do Esta- do de Santa Catarina. Sua centralidade se dá principalmente pela presença do expressivo polo agroindustrial que na última década tem impulsionado a ida de inúmeras populações migrantes como a de senegaleses, venezuelanos, congoleses e principalmente de haitianos. O antropólogo haitiano Handerson Joseph tem sido fundamental no que se refere a pensar os deslocamentos haitianos históricos e contemporâneos. Do ponto de vista etnográfico, ele "mostra o termo diáspora associado à mobilidade transnacional como constitutiva da trajetória de vida das pessoas e dos horizontes de possibilidades delas" (JOSEPH, 2015, p.54). Como um exemplo do uso cotidiano do termo, Joseph menciona que "as músicas haitianas produzidas no exterior são chamadas músicas de diáspora”. (ibidem., p.53)

Meu deslocamento para esta cidade se deu por motivos de trabalho: nela fui professor de música em diferentes espaços e através dessa atuação passei a conhecer músicos do Haiti, a receber convites para integrar grupos, participar de shows, gravações e acessar uma rede migrante na cidade. Menciono isto porque é partir destas entradas como músico, neste campo, que posteriormente passei a situar essas experiências em termos de uma tese de etnomusicologia, atualmente em andamento. Minha experiência nesta cidade sempre foi atravessada por estranhamentos e estar ali também me colocava em uma condição de migrante, embora isto tenha sempre implicações muito distintas das de meus interlocutores.

\section{Um rap haitiano sobre a cidade}

Malko J. é um jovem rapper e DJ natural da cidade haitiana Porto Príncipe e vive em Santa Catarina há quase dez anos. Logo que cheguei em Chapecó ouvi falar de seu trabalho. Neste momento ele recentemente havia lançado o 
vídeo clipe de sua música "Meu Desabafo", ${ }^{6}$ que contém cenas gravadas dentro do estádio de futebol local. A música e o vídeo repercutiam e circulavam pela cidade. Neste momento, Chapecó ainda estava impactada pelo trágico acidente de avião sofrido pela equipe do clube de futebol Chapecoense em direção à Colômbia, ao final de 2016. Malko J. inicia essa música mencionando a expressão "força Chape, força Chape" que a partir do acidente passou a denotar, além de apoio ao clube de futebol, apoio à cidade e seus habitantes.

Posteriormente a este primeiro contato com o trabalho do músico, conheci outra composição sua, a qual me deterei aqui, e que foi criada em parceria com um coletivo de rappers da cidade. Intitulada "Terra de Coronéis", a música refaz o histórico da cidade, reconta um famoso assassinato na principal praça na metade do século XX, ironiza o slogan de cidade agroindustrial e de cidade do trabalho, e aponta sua face xenófoba e racista.

A primeira parte da letra é cantada pelo grupo Sociedade Rap de Rua, grupo que também assina a composição, e a segunda parte por Malko J.:

o Brasil é meu lugar mesmo com tudo bagunçado Aqui já não é mais só futebol, carnaval Multi territorial, cultural, racial, multinacional, o animal irracional

Governo sangue suga até corrupção astral Equem se salva nessa guerra na luta pelo poder

E quem só quer poder trabalhar sem sofrer E quem veio pra cá atrás de uma vida melhor Esentea dor dessemaldito algoz

Chegar numa entrevista e a humilhação de ser barrado porque quando te ligaram tu não disse queera afro

6 Link do videoclipe "Meu Desabafo" disponível na plataforma youtube: https://www.youtube.com/watch?v=Cnv-IrMHxt8

7 Link da música "Terra de Coronéis" disponível na plataforma youtube: https://www.youtube.com/watch?$\mathrm{v}=75 \mathrm{~nm} 2 \mathrm{AiOOCW}$
É lamentável, o câncer não curou do passado Olha o estrago que as mente do passado ainda causam

E trazem a lembrança da barbárie

Os irmãos queimados vivos por um bando de covardes que levam os nomes de praças e ruas

Difamando o povo e reprimindo a luta Sentimento verdadeiro é o amor pelo dinheiro O ódio e a ganância são os pilares do templo Com milhões de fiéis adorando o demônio e beijando seus pés

SP, SC a história é a mesma

Safado de barriga cheia roubando merenda Capital de agroindústria, turismo de negócio, colono escravo no "migué" que era sócio

E patrocinam o time, financiam campanha, trabalhador explorado já não tem esperança

Inventam a crise mas tudo milionário, pro povo se humilhar, aceitar qualquer salário

Artimanhas que vão da prefeitura ao senado, montando o verdadeiro crime organizado

Morador despejado, índios executados, sem terra ocupa onde impera o descaso

Estudante espancado, professor humilhado pelo direito da escola e condição de trabalho De que adianto o poder se o espírito é fraco? De que adianta a luz e os olhos fechados? Se o povo não lutar vai viver sufocado, na terra dos coronéis que comandam o estado

É um rapaz caribenho, latino americano Eu sei que os povos sofrem e eram escravizados Os negros indignados, indígenas, caboclos, muitos foram matados, calados

haha vâmo seguindo, haitiano ainda é assassinado, discriminado

Não somos coitados porque somos Toussaint, Dessalines, Pétion

Somos humilhados porque aqui não tem ninguém que nos represente Imigração no Brasil a cada dia fere nosso orgulho 
Dão vinagre por água ao negro, e empresário paga metade de um salário mínimo

Um sorriso falso é o pagamento do trabalho Achar serviço é fácil, mas na hora da entrevista por causa da cor da nossa pele eles matam nosso currículo

Caraca, século 21 ainda tem o preconceito, até na procura do trampo tem um conceito

A cidade é um campo, quem fica em pé tá no comando

Sou preto, sim! Abordagem fora da lei eu não aceito e nem me calo

E prefiro voltar do que trabalhar pela força na escravidão moderna por mão de obra

I'm to be haitian, valeu!

Malko J. e o coletivo Sociedade Rap de Rua (SSR) de Chapecó apontam, tanto diretamente na música quanto nos seus discursos em torno dela, uma cidade migrante e, nela, a experiência recente de sujeitos e comunidades migrantes e refugiadas. Apontam uma cidade com um histórico de migrações que remontam aquelas ocorridas no final do século XIX por italianos, alemães e poloneses. Apontam uma cidade industrial que oferece empregos precarizados. Apontam o preconceito da cidade. Mencionam um assassinato em praça pública pelos "coronéis daquela terra”, referência que aparece no título da canção. Seguindo a noção nexo como colocada pelo musicólogo ganês Kwabena Nketia, podemos dizer que esta canção está operando como um nexo entre subjetividades coletivas e individuais, e entre experiências do passado e do presente. Como proposto por Nketia, nexo indica "um meio de conexão ou simultaneidade entre domínios - que de outra forma seriam distintos institucionalmente (e analiticamente) - trazidos juntos para dentro da estrutura do evento musical"8 (CHERNOFF, 1989, p.2).

Malko, diferente de outros músicos haitianos que vivem em Chapecó e naquela região oeste do estado, tem uma circulação mais ampla no circuito de música local, especialmente na cena rapper, participando da organização de batalhas de MC's e de festas como DJ em boates centrais. Sobre o rap Terra de Coronéis, Malko me diz que com essa música passou a sofrer abordagens policiais mais violentas, considerando o teor de provocação que a música contém. Isso me remete a um episódio ocorrido alguns anos antes do lançamento dessa música, em torno de um livro que aborda esse histórico violento da cidade (HASS, 2013). Ataques endereçados à autora por escrever a respeito de um linchamento em praça pública nos anos 1950, ${ }^{9}$ episódio que também aparece no rap aqui em questão, foram justificados pelo fato do livro evidenciar uma elite local que conecta um passado e presente na região. Creio que a existência de um rap que recoloca estas questões, enunciado por um artista haitiano, complexifique a trama étnico-racial, política e econômica que compõe a cidade.

Procuro conectar estas experiências em torno do sonoro com o que apresentam Ana Hofman e Srdan Atanasovsky (2017) sobre contextos de conflito e sobre grupos minoritários. Ao falarem de memórias sônicas enquanto intervenções nos territórios pós-lugoslávia, especificamente Eslovenos e Sérvios, se referem a ações sonoras como modos de participação política no enfrentamento às políticas urbanas de silenciamento.

8 Esta tradução, não publicada, foi feita em 2011 pelo Grupo de Estudos Musicais (GEM) ligado ao Programa de Pós-Graduação em Música da UFRGS. Foi traduzida coletivamente por Paulo Muller, Ivan Paolo, Marília Stein, Luciana Prass, Paulo Murilo, Mario Maia, Leonardo Cardoso e Maria Elizabeth Lucas.

9 Este episódio também é contado no documentário "A primeira pedra" (2018) do diretor Vladimir Seixas e produzido pelo canal Futura. 
Mencionando o caso de um coral na capital Liubliana que se propõe a ocupar a cidade e que se baseia em repertórios atribuídos à determinados códigos militantes, dizem que este coral busca "reintroduzir histórias marginalizadas/ 'escondidas' da cidade (de mulheres, migrantes, refugiados etc.) no seu mapa e revelar paisagens urbanas 'inapropriadas'” (HOFMAN, ATANASOVSKY, 2017, p.95).

No caso em torno da música de Malko J. e do coletivo SSR, ao mesmo tempo em que apresentam e reafirmam as questões que se referem às migrações do século XXI, sobre ser negro migrante naquela cidade, trazem à tona um panorama profundo desta cidade. Mais do que recolocar estes episódios históricos em cena recolocar o "inapropriado" -- as articulações em torno dessa música atualizam questões ligadas ao racismo brasileiro e à experiência haitiana e migrante negra no Sul do Brasil no século XXI. A canção explicita essa experiência migrante e diante disto estabelece pontos de contato e pontos de tensionamentos. Por pontos de contato me refiro a rede criada por Malko entre rappers e outros artistas no Brasil, e por pontos de tensionamentos me refiro aos efeitos violentos amplificados pela performance dessa música.

\section{Show virtual, reverberação e silenciamento}

A Valide Konpa é um coletivo de músicos haitianos dedicado ao gênero musical Konpa Direk, expressivo da cultura haitiana. O grupo foi iniciado em 2019 e conheci Olson, da cidade haitiana Petit Gôave e um dos fundadores do grupo, a partir de seu telefonema me convidando para participar do coletivo como tecladista. Meu contato havia chegado até ele através do rapper Pitit Guerline Nan (PGN), também um jovem produtor musical haitiano com quem tenho trabalhado. O grupo Valide Konpa é uma frente musical na cidade e região e tem um diálogo di- reto e engajado com as comunidades haitianas e com suas articulações, eventos e festas. As festas haitianas, para além das redes entre músicos, são mobilizadoras das comunidades como um todo. É frequente que as festas tenham uma ampla programação com rappers, DJs, grupos de dança, e ainda pessoas envolvidas em torno da culinária e bebidas típicas, com apoio de empreendedores haitianos que tem estabelecimentos em Chapecó, e com apoiadores do Haiti. Olson, ao falar da sua chegada na cidade, sobre a criação da banda, sua busca por músicos e sua iniciativa nas produções de festas, aponta esses eventos como significativos para o acesso a lazer, a despeito de suas jornadas exaustivas e precarizadas de trabalho, e do direito à cidade.

[...] Eu tenho uma relação muito boa com as pessoas [pessoas do Haiti em Chapecó] porque muitas delas gostam da minha banda, porque esse é o ritmo deles, de haitianos... e que eles não têm aqui, só a banda haitiana que vai trazer diversão...só a banda. Antes, aqui, não se divertia nada. Depois do trabaIho era voltar para casa, dormir, amanhã trabalhar, chegar, dormir, amanhã trabalhar. Só que agora que tem essa banda, a cada dia que fazemos uma festa as pessoas gostam, vão se divertir, vão dançar, vão comer, vão conversar. (OLSON, entrevista online realizada em set. de 2020)

Um dos efeitos do ativismo da banda entre as comunidades migrantes, tal como Olson coloca, tem sido a entrada de grupos haitianos de música e de dança em eventos oficiais organizados por setores culturais da cidade, e isto também tem imposto novas situações. Do ponto de vista de uma práxis sonora ${ }^{10}$ (ARAUJO, 2013), tomo os

\footnotetext{
10 “[...] por meio da categoria práxis sonora enfatizo a articulação entre discursos, ações e políticas concernentes ao sonoro, como esta se apresenta, muitas vezes de modo sutil ou imperceptível, no cotidiano de indivíduos (músicos amadores ou profissionais, agentes culturais, empreende-
} 
discursos estigmatizantes e as práticas hegemônicas (a música incluída) como um dos discursos colocados em jogo neste cenário urbano. Discursos oficiais, como são aqueles enunciados pelos setores culturais e artísticos institucionais, e que, por vezes, fazem determinada leitura exotizante dos movimentos migrantes, são lidos aqui neste registro.

Ao longo do ano de 2020, sob todos os efeitos da pandemia que impactaram as atividades culturais, shows, ensaios, gravações etc., participei junto com uma banda Valide Konpa da inscrição em um edital local que estava apoiando financeiramente artistas nas produções de shows transmitidos virtualmente. Eles foram aprovados neste edital e auxiliei na organização deste show. A pandemia impunha, então, outros modos de "estar em campo", e do ponto de vista da pesquisa etnomusicológica foi interessante estar ali naquele evento virtual, interagir e rever interlocutores e amigos, ouvir o setlist da banda e acompanhar os comentários do público. Este show virtual teve cerca de 20 mil visualizações com público interagindo de países como Argentina, Chile, Peru, EUA, República Dominicana, Canadá, França e Bélgica, além de Haiti e Brasil.

O setlist desta noite, assim como tem sido nos outros shows, apresentou um repertório baseado em grupos musicais de konpa reconhecidos internacionalmente e radicados em países que compõem a diáspora haitiana. Aquela performance em Chapecó recolocava, assim, agora por meio da música, a cidade em uma rede transnacional. Isto também nos recolocava questões em torno da noção de fronteira,

dores, legisladores), grupos (coletivos de músicos, públicos, categorias profissionais), empresas e instituições (por exemplo, sindicatos, agências governamentais e não-governamentais e escolas), tomando como pano de fundo a política e as lutas pela cidadania plena e pelo poder no Brasil hoje. (ARAÚJO, 2013, p.9) agora também virtuais, e como seus limites são mediados em um contexto migratório (MEZZADRA, NEILSEN, 2013). Além do público haitiano presente virtualmente neste show (a partir dos países mencionados anteriormente) há uma recorrente coparticipação na organização desses shows e festas que atravessam esses espaços transnacionais. Cartazes de divulgação, o desenho de figurino para os shows, as gravações de beats e outras produções são com frequência resultado de colaborações com parceiros e amigos que estão no Haiti. Quero situar, com isto, o quanto a dimensão online atravessa as vidas diárias e musicais de meus interlocutores.

Ao término da transmissão online, as pessoas que estavam no local, músicos e equipe técnica de transmissão, sofreram uma abordagem policial sob falsa alegação de festa clandestina em meio a pandemia. Mesmo sendo apoiado por uma instituição pública local (Secretaria de Cultura) o evento, ainda assim, foi alvo de violência policial. Um jornal sensacionalista local, que no dia seguinte noticiou o ocorrido na mesma linha do discurso policial, foi alvo de comentários xenófobos em sua publicação. Esse episódio da Live pode ser situado em uma relação de continuidade com outros que ocorreram anteriormente em torno de shows, ensaios e festas da comunidade, em que questões acionadas pelo sonoro apresentam posições racistas e xenófobas. Apresento este episódio na medida em que ele sugere o som como presença migrante-negra-haitiana no bairro, em uma cidade majoritariamente branca, ao mesmo tempo em que sugere o som como violência. O som que reverbera naquele território enquanto afirmação migrante, que articula e conecta uma rede, é também o som que provoca reações de moradores, vizinhança, polícia, que produz rupturas e dispersões. A etnomusicóloga Ana Maria Ochoa, a respeito de uma acustemologia da violência, ${ }^{11}$ diz que:

110 termo acustemologia é de Steven Feld e foi criado 
Si la irrupción de la fuerza de las violencias en eventos concretos interrumpe nuestra vida cotidiana, y nos ubica en el límite entre lo humano y lo inhumano (Uribe Alarcón 2004), su memoria y elaboración las involucra en las tramas temporales del miedo y la esperanza, la memoria y el olvido, el silencio asumido y el silenciamiento obligado, la no escucha y lo audible. (OCHOA, 2006, n.p).

Ao reivindicar uma acustemologia da violência, Ochoa assinala que as sociedades recorrentemente compreendem os processos violentos como algo exterior ao social. A noção de ruído é, assim, usada como metáfora musical para aquilo que não funciona na sociedade. Segundo Ochoa, o "reconhecimento de que as violências surgem 'de dentro da esfera social', portanto, também implica o desmantelamento desta metáfora sócio musical e da ontologia musical em que se baseia, o ruído como externo à música e ao acusticamente agradável" (ibidem., n.p). E isto implica, de acordo com ela, em reconhecer que são políticos os limites entre o que se considera som e música e a respeito do entendimento da música apenas como prazer e sociabilidade. Compreender práticas musicais como ruídos, que poderiam ou deveriam ser eliminadas, são processos que partem, assim, do próprio sonoro.

Ana Maria Ochoa diz que o reconhecimento disto nos permite "traçar a maneira como se articulam os conhecimentos sobre a esfera pública e sobre o musical em longas tramas históricas de exclusão que podem ser acionadas, consciente ou inconscientemente, em momentos de violência”. As festas haitianas que mobilizam as comunidades haitianas e migrantes na cidade, produzem potências sonoras que sus-

para "sugerir uma união entre acústica e epistemologia e investigar a primazia do som como uma modalidade de conhecimento e de estar no mundo" (OCHOA, 2006, n.p). citam reações repressivas. O episódio mencionado anteriormente em torno da transmissão virtual refere-se mais diretamente à reação do Estado, por meio da polícia local. No entanto, ao longo destes últimos anos acompanhando os trajetos desses músicos pude observar modos violentos e estigmatizantes lançados a partir de outras posições como por pessoas ligadas a casas de show e bares, por técnicos de som e músicos locais e por determinado setor progressista/alternativo. Ainda, as festas haitianas, ao contratarem pessoas locais para serviços de segurança, equipes de som, iluminação e transporte, criam situações novas na cidade. Tornase, por exemplo, recorrente que em uma festa em que participam trezentas pessoas negras, as pessoas encarregadas de prestarem os serviços são brancas. Creio que estes exemplos complexifiquem ainda mais as noções fixas a respeito das relações entre uma cidade majoritariamente branca versus comunidades migrantes negras. Creio que questões como estas coloquem camadas nos modos como as comunidades haitianas se articulam, como reorganizam seus discursos diante de situações adversas, e como produzem outras cidades.

\section{Conclusões}

A partir do trabalho de dois músicos/grupos haitianos, propus uma possibilidade de escuta da cidade de Chapecó. Em torno das experiências e questões suscitadas por Malko J. e pela banda Valide Konpa, sugeri uma escuta da cidade sob a perspectiva dos fluxos e deslocamentos migrantes haitianos.

Tenho articulado o termo sonoro junto ao musical a fim de pensarmos, para além da noção estabelecida de música, ${ }^{12}$ um campo de

12 "Por música, então, os etnomusicólogos se referem ao complexo total de interação social e padronização cultural relacionados à institucionalização do som estruturado. 
forças vibracionais (GOODMAN, 2010) que nos permita considerar noções como ruído, silêncio, silenciamento, paisagem sonora, assim como os limites, demarcações e interdições que têm sido acionadas em torno do som e de performances musicais. Acompanhar os trajetos de músicos e de suas músicas ao longo da cidade, nos tem feito pensar esse sonoro em termos de encontros entre "mundos musicais locais" e "mundos musicais migrantes", sendo estes encontros efetivados não sem tensões e violências. A "poética da relação” do martinicano Édouard Glissant (1990) nos fala sobre as possibilidades de considerarmos a dimensão conflitiva em torno da ideia de relação. Creio que com Glissant podemos reconsiderar, também, uma noção recorrente nos estudos sobre migração que é a de "integração social”, e colocar em xeque outra que é a de "diálogo musical". Nos recortes etnográficos trazidos aqui, nesse cenário sonoro-musical, isto se apresenta como algo mais complexo e contraditório.

Por fim, música, neste contexto migratório aqui apresentado, se refere também a modos de presença na cidade, a modos de participação no debate público, de participação política, à produção de espaços transnacionais ${ }^{13}$ e à criação de conexões (sejam elas com a so-

Para evitar pressuposições sobre o significado musical, os etnomusicólogos têm tentado abordar a música como um complexo cultural de forma similar ao modo como os antropólogos têm abordado o estudo da religião, isto é, sem referência a uma noção filosófica ou universalista de um impulso religioso ou de uma realidade metafísica; em um contexto musical, tal abordagem evita que se dê à música o status de um a priori" (CHERNOFF, 1989, p.2). Sobre esta tradução vide nota de rodapé 7 .

13 "Enquanto a teoria dos 'sistemas migratórios' chama atenção para a densidade histórica dos movimentos das populações, antropólogos se debruçam em suas análises sobre os novos espaços sociais transnacionais que estão sendo formados a partir dos comportamentos e práticas sociais através dos quais a autonomia das migrações se expressa em sua materialidade" (MEZZADRA, 2012, p.83) ciedade local, sejam com o Haiti, sejam com os múltiplos territórios da diáspora haitiana pelo mundo). Sandro Mezzadra (2012, p.73), ao propor uma perspectiva de análise das "políticas de mobilidade" que enfatize "a dimensão subjetiva no interior das lutas e enfrentamentos que constituem materialmente o terreno dessas políticas", aponta as redes afetivas como algo fundamental na composição dos fluxos migratórios. Diante disto, e em diálogo com o papel desempenhado pelas redes afetivas, busquei situar aqui o papel que as redes sonoras (com seus nexos, territorializações, amplificações, presenças, afirmações e tensionamentos) têm desempenhado na composição desta migração haitiana nesta cidade do Sul do Brasil.

\section{Referências}

ARAUJO, Samuel. Entre muros, grades e blindados; trabalho acústico e práxis sonora na sociedade pós-industrial. El oído pensante 1 (1). 2013. Disponível em: http://ppct.caicyt.gov.ar/ index.php/oidopensante. Acessado em: 20 de mar. de 2021.

ARAÚJO, Samuel et allí. A violência como conceito na pesquisa musical, reflexões sobre uma experiência dialógica na Maré. Transcultural Music Review 10, 2006. Disponível em: www. sibetrans.com/trans/trans10araujo.htm. Acessado em: 20 de mar. de 2021.

BAILY, John. So Near, So Far: Kabul's Music in Exile. Ethnomusicology Forum, vol.14, $n^{\circ} 2$, 2005, pp.213-33.

CHALCRAFT, Jasper; SEGARRA, Josep Juan; HIKIJI, Rose Satiko Gitirana. Bagagem Desfeita: A Experiência Da imigração Por Artistas Congoleses. GIS - Gesto, Imagem E Som - Revista De Antropologia 2 (1). São Paulo, Brasil, 2017. Disponível em: https://doi.org/10.11606/issn.25253123.gis.2017.129448. Acessado em: 20 de mar. de 2021. 
CHERNOFF, J. M. The relevance of ethnomusicology to anthropology: strategies of inquiry and interpretation. Em: DjeDje, Jacqueline (ed.) African musicology: current trends. Los Angeles, Univ. of California Press, v.1, 1989, p. 59-92.

CUSICK, Suzanne G. 2006. Music as torture/ Music as weapon. Transcultural Music Review 10. Disponível em: www.sibetrans.com/trans/ trans10/cusik.htm Acessado em: 10 de mar. de 2021.

DIEME, Kassoum. O Haiti e suas migrações. BERSANI, Ana Elisa; JOSEPH, Handerson (org.). Dinâmicas migratórias haitianas no Brasil: desafios e contribuições. Temáticas: Revista dos pós-graduandos em Ciências Sociais. IFCH/UNICAMP, n.49/50, 2017, pp.17-48.

EWELL, Philip. Music Theory and the White Racial Frame. Music Theory Online, vol. 26, n.2, s/n, set. 2020. Disponível em: https://mtosmt.org/issues/mto.20.26.2/mto.20.26.2.ewell. html?fbclid=IwAR1dSc4pSk6bBaW79vRFPJbLFMF1tXsr79t4iSorWnm_OU3lpJ9EnWGcd20. Acessado em: 25 de mar. de 2021.

GLISSANT, Édouard. Poetics of Relation. University of Michigan Press, 1990.

GOODMAN, Steve. Sonic Warfare: Sound, Affect, and the Ecology of Fear. Cambridge: The MIT Press, 2010.

HASS, Monica. O linchamento que muitos querem esquecer: Chapecó, 1950-1956. Argos Editora, Chapecó, SC. 2013.

HEMETEK, Ursula. Mundos musicais inesperados de Viena: imigração e música. Em: CÔRTE REAL, Maria de São José (org.), Revista Migrações - Número Temático Música e Migração, n.7, Lisboa: ACIDI, out.2010, pp.119-146.

HOFMAN, Ana; SRDAN, Atanasovski. Sonic memory interventions against politics of urban silencing. музикологијА / Musicology. v.22, 2017.

INGOLD, Tim. Against Soundscape. In: CAR-
LYLE, Angus (ed.), Autumn Leaves: Sound and the Environment in Artistic Practice. Paris: Double Entendre, 2008, p.10-13.

JOSEPH, Handerson. Diáspora. Sentidos sociais e mobilidades haitianas. Horizontes Antropológicos, Porto Alegre, ano 21, n. 43, p. 51-78, jan./jun. 2015. Disponível em: https://doi. org/10.1590/S0104-71832015000100003 Acessado em: 10 de abr. De 2021.

Diáspora. NEIBURG, Federico (Org). Conversas etnográficas haitianas. Rio de Janeiro: Papéis Selvagens Edições, 2017, pp.190-215.

KUN, Josh. The aesthetics of allá: listening like a sonidero. Em: RADANO, Ronald; OLANIYAN, Tejumola (org.). Audible Impire: music, global politics, critique. Duke University Press, Durham, London, 2016, p.95-116.

LA BARRE, Jorge de. A outra afinação do mundo: os territórios sonoros. Revista Interfaces 16 (1), 2012, 117-127.

LÜHNING, Angela; TUGNY, Rosângela Pereira de (Org.). Etnomusicologia no Brasil. Salvador: EDUFBA, 2016.

MEZZADRA, Sandro. Multidão e migrações: a autonomia dos migrantes. ECO-PÓS, UFRJ, v.15, n.2, 2012. Disponível em: https://revistaecopos. eco.ufr.br/eco_pos/article/view/900. Acessado em: 10 de abr. de 2021.

MEZZADRA, Sandro; NEILSEN, Bret. Borders as Method, or, the Multiplication of Labour. Durham, North Carolina: Duke University Press, 2013.

OCHOA, Ana Maria. A manera de introducción: la materialidad de lo musical y su relación con la violencia. Dossier Música, silencios e silenciamentos: música, violencia y experiencia cotidiana. Revista da Sociedad de Etnomusicología, TRANS, v.10, 2006. Disponível em: https://www. sibetrans.com/trans/articulo/142/a-manera-de -introduccion-la-materialidad-de-lo-musical-ysu-relacion-con-la-violencia. Acessado em: 05 
de abr. de 2021.

QUEIROZ, Luiz R. S. Traços de colonialidade na educação superior em música do Brasil: análises a partir de uma trajetória de epistemicídios musicais e exclusões. Revista da ABEM, vol. 25, n. 39, p. 132-159, 2017.

. Até quando Brasil? Perspectivas decoloniais para (re)pensar o ensino superior em música. Revista PROA vol. 10, n. 1, p. 153-199, jan. -jun. 2020

SASKIA, Sassen. Três migrações emergentes: uma mudança histórica. Sur: Revista Internacional de Direitos Humanos, v.13, n.23, 2016, p.2942.

SARDO, Susana. Pround to be a Goan: memórias coloniais, identidades pós-coloniais e música. Em: CÔRTE REAL, Maria de São José (org.), Revista Migrações - Número Temático Música e Migração, n.7, Lisboa: ACIDI, out.2010, pp.5573.

STEINGO, Gavin; SYKES, Jim (org). Remapping sound studies. Duke University Press, Durham, London, 2019.

SHELEMAY, Kay Kaufman. Let jasmine rain down: Song and remembrance among Syrian Jews. Chicago, IL, and London: University of Chicago Press, 1998.

WESTERN, TOm. Listening with displacement: sound, citzenship, and disruptive representation of migration. Migration and Society: Advances in Research 3, 2020, p.294-309.

\section{Daniel Stringini}

Doutorando em Musicologia/Etnomusicologia pelo Programa de Pós-Graduação em Música da Universidade Federal do Estado do Rio de Janeiro com pesquisa na temática Práticas Sonoras em Fluxos Migratórios Contemporâneos. Mestre em Etnomusicologia/Musicologia pelo Programa de Pós-Graduação em Música do Instituto de Artes da Universidade Federal do Rio Grande do Sul (UFRGS), orientado pelo etnomusicólogo Dr Reginaldo Gil Braga, recebendo bolsa do Conselho Nacional de Desenvolvimento Científico e Tecnológico (CNPq). Licenciado em Música pela Universidade Federal de Santa Maria (UFSM), 2008-2012, tendo sido Bolsista de Iniciação Científica do grupo FAPEM: Formação, Ação e Pesquisa em Educação Musical,

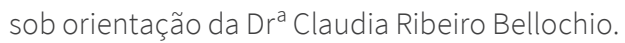
Integra o Núcleo de Etnomusicologia da UFRGS - ETNOMUS UFRGS - Núcleo de Estudos em Música do Brasil e América Latina, coordenado pelo etnomusicólogo Dr ${ }^{\circ}$ Reginaldo Gil Braga. Integra o projeto de extensão Cultura Popular e Universidade: Saberes em Diálogo, do curso de Música da Universidade Federal do Estado do Rio de Janeiro (UNIRIO), coordenado pelo etnomusicólogo Drº Vincenzo Cambria. 